\title{
Confusión de confusiones: identidad y cultura
}

\author{
Claudio GuilléN \\ Real Academia Española
}

RESUMO: $\bigcirc$ ARTIGO VERSA SOBRE $\bigcirc$ TRATAMENTO SIMPLIFICADO QUE TENDE A SER APLICADO SOBRE CONCEITOS COMPLEXOS COMO IDENTIDADE E CULTURA E APONTA DEFINIÇÕES CABÍVEIS QUE PODEM SER APLICÁVEIS NO ÂMBITO PESSOAL, SOCIAL E ANTROPOLÓGICO. DESTACA-SE, AINDA, A NECESSIDADE DE SE ENTENDER E ABSORVER AS DIFERENCCAS, SOBRETUDO NO UNIVERSO AMPLO E PLURAL QUE COMPÕEM OS PAÍSES QUE TÊM O ESPANHOL COMO IDIOMA OFICIAL.

RESUMEN: EL ARTÍCULO VERSA SOBRE EL TRATAMIENTO SIMPLIFICADO QUE TIENDE A APLICARSE A UNOS CONCEPTOS COMPLEJOS COMO IDENTIDAD Y CULTURA, APUNTANDO DEFINICIONES CABIBLES, QUE SE PUDEN APLICAR EN EL ÁMBITO PERSONAL, SOCIAL Y ANTROPOLÓGICO. SE VOLCA, ASIMISMO, PARA LA NECESIDAD DE ENTENDERSE Y ABSORBER LAS DIFERENCIAS, EN PARTICULAR EN EL UNIVERSO AMPLIO Y PLURAL COMPUESTO POR LOS PAÍSES QUE TIENEN EL ESPAÑOL COMO IDIOMA OFICIAL.

PALAVRAS-CHAVE: IDENTIDADE, CULTURA, MULTIPLICIDADE, EQUIVOCOS, SIMPLIFICAÇÃO. PALABRAS-CLAVE: IDENTIDAD, CULTURA, MULTIPLICIDAD, EQUIVOCOS, SIMPLIFICACIÓN. 
o puede no admirarme y no alegrarme el corazón la amplitud que caracteriza esta magna reunión, la riqueza de componentes que la integran, la voluntad de mutuo entendimiento y de progreso con la que los unos oyen y atienden a los otros. La espaciosidad americana maravilla a quienes venimos de una Europa cuya dimensión esencial es la pequeñez. De buenas a primeras me encuentro también con que los temas que nos van a preocupar son vastísimos; y si escribo vasto con $v$, y no con $b$, no es por mi condición de académico, sino porque no podemos no ser conscientes de la complejidad de los términos que nos toca utilizar. Yo quisiera acentuar hoy la necesidad de no caer en la trampa de los simplificadores, manteniendo un nivel razonable de claridad conceptual cuando manejamos estos términos rebosantes de ambigüedades y malentendidos. Ahora mismo me explicaré, señalando dos conceptos que han sido y son objetos de constantes abusos y malos tratos: el de identidad y el de cultura. El de "globalización" lo dejo gustoso en manos de los expertos. ${ }^{1}$

Con las identidades ocurre lo mismo que con las verdades, que dependen no de unas cosas que están ahí, más allá de nosotros, sino de las palabras que pronunciamos acerca de esas cosas. Las verdades no andan por el mundo, dispersas e independientes, como tampoco las mentiras, ya que en primera instancia son el contenido de unos enunciados verbales. El hablante es quien produce palabras verdaderas o falsas. La urgencia de definir o caracterizar identidades responde asimismo o bien a una necesidad o una inclinación de nuestro pensamiento, o bien, creo que en muchos casos, a una exigencia de los demás, que desde fuera nos imponen tan delicada tarea.

Identificar tiende pues a ser una forma de pensar, es más, pertenece originariamente al ámbito del recto razonamiento. Desde la gran filosofía griega se ha venido destacando el principio de identidad como fundamento del más general de los lenguajes, que es la lógica. Algo no puede ser y no ser a la vez, pretendiendo, por ejemplo, ser lo contrario de lo que es. Ahora bien, aquello que era un principio del razonamiento pasó ya con Pármenides a aplicarse al ser mismo de las cosas, reduciéndolas a lo idéntico, suprimiendo la multiplicidad en aras de su adecuación al pensamiento. La realidad tenía que

\footnotetext{
${ }^{1}$ Reproduzco aquí con algunos cambios la ponencia leída en el III Congreso de la Lengua Española, en Rosario el 14 de noviembre de 2004.
} 
ser pensable desde el principio de identidad. Otras muchas interpretaciones no se dieron por satisfechas con esta subordinación de la inteligencia de los seres a las normas o los procedimientos que permitieran pensarlos mejor; o bien concluyeron, con Leibniz, que la definición de una identidad equivalía a la búsqueda de su esencialidad y su permanencia. Por otro lado, evidente era que la conciencia de la variedad, del cambio y de la contradicción, en el ámbito ante todo de las sociedades y las artes, tenía que conducir a posturas reñidas con la extensión totalizadora de los principios lógicos. Hace casi cien años, en 1908, el pensador francés Émile Meyerson, en Identité et réalité, denunciaba el prurito de violentar la realidad en interés o beneficio de la identidad.

En el ámbito que nos ocupa, el de las condiciones que envuelven el ejercicio del lenguaje y de la creación literaria o artística en los países hispánicos, salta a la vista que el traslado de la identidad como forma de pensamiento a la percepción de las obras mismas y los actos mismos provoca de entrada una constante experiencia de la diversidad. Se sabe que en España, con resultados notoriamente positivos, se puede ser a la vez catalán, español y europeo. El camino que se viene emprendiendo en Europa supone a cada paso esta aceptación de la simultaneidad. Pero hay que aprender de situaciones menos sencillas. Según los momentos, o según el estrato de la personalidad o de la sociedad de la que se trate, se puede ser a la vez español y no serlo; se puede ser mexicano y también no serlo. De otra forma, sería difícil percibir el carácter o la situación de tantos exiliados, o de muchos diaspóricos; o acercarse a las vidas de los más humildes emigrantes; Como también a las de grandes artistas y creadores. ¿Quién o qué era en el fondo Kafka? ¿Quién o qué era Picasso? Tengo presente ahora a un colega admirable, expulsado de su ciudad natal, Jerusalén, cuando era muy joven, luego doctor por Harvard en Literatura comparada, Edward W. Said. En uno de sus libros principales, cultura e imperialismo (1993), elabora Said con especial delicadeza autocrítica una modalidad de pensar que él compara con el contrapunto musical. Según él la mentalidad imperial no es sólo política; es cultural, y moralmente coincide con la soberbia. Vivimos en mundos plurales y el gran enemigo es la simplificación. Ninguna visión tiene total hegemonía sobre el terreno que contempla. Ninguna cultura es monolítica. Ninguno de nosotros es sólo una cosa. Los esfuerzos de los ex colonizados más lúcidos nos hacen comprender que es equivocado remedar 
el nacionalismo de los colonizadores. Más allá de los separatismos, Said insiste, hay que buscar "realidades humanas más amplias, más generosas, de comunidad entre las culturas, los pueblos y las sociedades." Nuevas alianzas, que supriman las fronteras intelectuales y políticas, indispensables comienzos nuevos, no tratándose, ni en Oriente Medio ni en ninguna parte, de poner en práctica un tipo ideal o un esquema fijo, han de arrancar de la "voluntad moral" de todos.

Forma mentis, ésta, que desde otros ángulos manifestaba a la perfección el malogrado Francisco Tomás y Valiente cuando escribía:

Ninguna identidad colectiva es total, ni sería bueno que pretendiera serlo. Siendo todas parciales e incompletas y de naturaleza heterogénea, hemos de aprender a sentirnos miembros de distintos círculos, individuos que no se identifican total y exclusivamente con nada ni con nadie, lo cual no significa la preferencia por el desarraigo individualista, sino el reconocimiento racional de una realidad social compleja en la que cada hombre es punto de intersección de distintos sujetos colectivos. ${ }^{2}$

Se puede empezar a percibir así una realidad social compleja, que ha de conjugarse con un reconocimiento asimismo racional del quehacer cultural, o de lo que se llama en general, para bien o para mal, cultura. Digo para mal porque en este terreno se introducen tantos equívocos, tantas simplezas y tantos tejemanejes políticos que se produce con frecuencia una algarabía ininteligible. Lo curioso es que los implicados no son incultos y sin embargo navegan tan tranquilos por un mar de confusiones.

Efectivamente todos conocemos la amplitud de sentidos a los que da cabida la palabra. Raymond Williams, en Keywords (Londres, 1976), muestra muy bien el dinamismo del término cuando explica que abarca un espectro cuyos dos extremos son "un proceso general de desarrollo intelectual, espiritual y estético", por un lado, y por otro, "una forma de vida" - a way of life. ${ }^{3}$

\footnotetext{
${ }^{2}$ TOMÁS Y VALIENTE, F.. "Nacionalismos en broma y en serio”. El País, Madrid: 14, 13 nov. 1994. ${ }^{3}$ WILLIAMS, Raymond. Keywords. Londres: 1976. Apud: The Cambridge History of Literary Criticism, IX. ed. C. Knellwolf y C. Norris, Cambridge, p. 161.
} 
Entre los dos sitúa "unas obras y prácticas de actividad intelectual y, especialmente, artística". El primer sentido, que llamaré $X$, es lo que el ilustre Claude Lévi-Strauss, denominaba "el cultivo del gusto y de la sensibilidad", como también el humanista Luis Vives al hablar de la cultura animi; y claro está que el contrario, a way of life, que llamaré $Z$, coincide con la tradicional acepción antropológica, que para Lévi-Strauss designaba "los usos, costumbres y creencias que comparten los miembros de una misma sociedad". Este concepto se ha prestado a formulaciones totalizadoras como la del lingüista Edward Sapir, que decía: "la cultura puede definirse como aquello que una sociedad piensa y hace". ${ }^{4}$ No había malentendidos al respecto en épocas más lúcidas que la nuestra, cuando por ejemplo el puertoriqueño Rubén del Rosario, hace cuarenta años, definía la cultura "como un conjunto de creencias, de costumbres y de objetos materiales propios de un pueblo o de un grupo de pueblos afines". ${ }^{5}$

El primer sentido, el que destacaba el gusto y la sensibilidad, y el sentido opuesto, el totalizador, implicaban muy directamente las experiencias de las personas mismas. El primero designaba una faceta del vivir personal; el segundo una faceta del convivir social. Pero las acepciones de Raymond Williams son tres. Se presenta también una idea medianera, la de las obras y prácticas ellas mismas, de índole artística o intelectual, que llamaré $Y$, de las que sin duda las personas de buen gusto disfrutan; pero que al reunirse bajo el título de cultura introducen una envoltorio de uso sobre todo institucional, universitario, periodístico y político. Es una cultura de segundo grado, crítica, antológica u organizada, cuya continuidad incumbe hoy a un invento de André Malraux, el Ministerio de cultura, cuando y donde lo hay. De él depende la buena marcha de importantes museos, teatros, sinfónicas, bibliotecas, colecciones de clásicos, qué duda cabe, aunque siempre con la severa restricción, que no se suele explicitar, de que se atiende exclusivamente a las prácticas y obras de una determinada nación; no sin perjuicio a ratos del ejercicio del gusto y la sensibilidad en cuestión.

${ }^{4}$ SAPIR, E. El lenguaje. México: 1956, p. 247.

${ }^{5}$ ROSARIO, R. del. América: lengua y cultura. Río Piedras: Universidad de Puerto Rico, 1961, s. p. 
Estos tres términos - el personal, el institucional y el antropológico - hoy se extreman y se confunden. No sé si recuerdan ustedes lo que vimos hace muchos años en una película de Bob Hope. El gran actor cómico viajaba por la África más profunda y vino a parar en una tribu que practicaba, entre otras cosas, el canibalismo. Aparece su jefe junto a una olla muy grande, dándole vueltas con un cucharón al guiso en que cuecen los miembros de un enemigo capturado. Ante las protestas del cómico, el jefe le contesta con un perfecto acento de Oxford: it's part of our cultura! "Compréndame, forma parte de nuestra cultura."

Consecuencia de semejante variedad de sentidos es el confusionismo al que aludía antes. Daré sólo dos ejemplos, dos frases, pronunciadas ambas hace poco por personas dignas de todo respeto. "El nuevo contexto de comunicación global implica obviamente una globalización de la economía, la política y la cultura." Por desgracia no considero tan obvia la naturaleza de la cultura que aquí se globaliza. ¿Todos podrán conocer el Libro del Tao? ¿Todos leerán el Martín Fierro? Y en otro lugar leo que compartir la misma lengua "supone caminar por el mundo con una cultura propia, con valores y visiones de la vida compartidas". Vale decir que los hispanohablantes tenemos en común, vamos a ver, ¿tal vez la cultura en la acepción de Bob Hope? ¿El que existan los mismos usos y las mismas costumbres en Yucatán, Asturias y el Río de la Plata? ¿O más bien, que todos heredamos una misma cultura $Y$, unas creaciones artísticas e intelectuales que no sólo emplean una misma lengua sino también constituyen un sistema cultural común? Si es que de veras existe, claro está, tal sistema.

Esta segunda significación es a todas luces la que aquí está en juego, la existencia de un acervo reunido, o cohesionado de obras de arte o de pensamiento de valor indudable. A este cuestionamiento conducía mi primera reflexión sobre la idea de identidad, entendida como tal, como una idea. Decíamos que la llamada identidad cultural no es una cosa sino el motor de unas reflexiones, de unas interrogaciones acerca de la naturaleza, la constitución, o, digamos sencillamente, el ser de las cosas. Y si algo sabemos es que la interrogación acerca del ser de los países hispánicos o ibéricos o iberoamericanos ha constituido a lo largo de muchos años una tradición de enorme interés, riqueza e importancia. Esta continuidad se ha presentado en ciertos terrenos como un proceso - al que acaso se sumen los resultados del presente coloquio.

Sin remontarse hasta Blanco White o Larra, basta con recordar a Unamuno, a Ganivet, a la función destacada que desempeñó la meditación 
autocrítica en las obras de la generación del 98 y sus aledaños, como más tarde en el pensamiento de Ortega y Gasset. Tras la Guerra Civil y en el exilio se fraguó la visión angustiada y rompedora de Américo Castro. Han sido innumerables los escritores, poetas o ensayistas que han buscado la expresión que revelara o desvelara el carácter del Nuevo Mundo, la "idea" de América o su "invención", sea de una de sus partes, sea de su conjunto, pero siempre desde el mismo dinamismo de la interrogación sobre el ser propio. ${ }^{6}$ Es una interrogación que en muchos casos es no ya una forma de investigación sino de creación. Pienso ahora, no les sorprenderá, en Martínez Estrada, por ejemplo, y su respuesta a los planteamientos de Sarmiento, y en Héctor Murena. En Zum Felde y los excelentes críticos literarios que fueron sus sucesores en Uruguay. O mirando hacia el Norte, en Leopoldo Zea y Octavio Paz. Ruego se me disculpe si toco rápida y parcialmente, y sin suficiente pericia unas cuestiones tan complejas.

Si la identidad es el objetivo virtual de un discurso de la identidad, ¿adónde nos puede éste conducir? ¿Ha sido en consecuencia posible, o lo es hoy, el descubrimiento de una identidad común o unitaria, no ya anhelada o futura como un ideal, sino patente y existente? Soslayo sin vacilar los comentarios simplificadores y superficiales del tipo Madariaga o Keyserling. Tampoco nos interesan sobremanera quienes describen lo que Luis Cardoza y Aragón, guatemalteco, llamaba "las plumas del guacamayo", o sea lo pintoresco y lo folclórico, confundiendo otra vez el modelo artístico-literario de cultura con el antropológico. Pero sí siguen siendo valiosos los intentos de caracterización de la literatura latinoamericana como parte y momento de ese discurso, de ese proceso de reflexión creativa al que me vengo refiriendo. Más que de folclore, se ha insistido muchas veces en los componentes populares de la escritura culta. Consideraba Ángel Rosenblat que era propio de la tradición hispánica en general el popularismo lingüístico: por ejemplo en Cervantes y Galdós. ${ }^{7}$ Escribía Francisco García Lorca acerca de su hermano Federico

\footnotetext{
${ }^{6}$ Sigue siendo muy útil al respecto el libro de ABELLÁN, José Luis. La idea de América: origen y evolución. Madrid: 1972.

${ }^{7}$ Véase ROSENBLAT, A. Lengua popular y lengua literaria en América. Caracas: 1969.
} 
que "el 'popularismo' es una forma de 'cultismo'. ${ }^{8}$ Sin duda esto ocurrió ya en el Siglo de Oro." Por otro lado, pensaba José Lezama Lima que la "expresión americana" era de tendencia barroca, o había de serlo. Preferencia, ésta, que sin duda coincidía con su propia voluntad de estilo, o con la de cierto Alejo Carpentier, conscientes los dos de la opulencia de una naturaleza y unos paisajes caribeños o sudamericanos; pero que, en mi opinión, sin olvidar la primera boga del gongorismo y determinada poesía de Sor Juana Inés de la Cruz, no puede emplearse hoy como rótulo crítico sin conceder al término barroco una esencialidad superior al cambio histórico y simplificadora del abundante y variopinto contexto en que tuvo que situarse cualquier corriente literaria dominante o dominada. Ángel Rama, que fue un crítico importante, de una envergadura y una agudeza excepcionales, aunque desigual a ratos, como la mayoría de los grandes escritores, y apasionado siempre, escribe una vez que durante la Colonia fue muy notoria "la fuerza del género", de un género literario como la épica y la crónica, así como después lo fueron "las escuelas en el siglo XIX y los movimientos y las corrientes en el siglo XX", según mostró el maestro Pedro Henríquez Ureña. Es una observación sin duda justa, desde un propósito sintético, y aplicable también a una amplia y multisecular historia de la literatura occidental, que abarca cambios e innovaciones en ambos lados del Atlántico. Los movimientos a los que se alude son de origen europeo, como el Romanticismo, el Positivismo y el Surrealismo, y no suponen, sobre todo durante el siglo posterior a la Independencia, una supeditación a modelos españoles sino una vinculación fundamental tanto de Hispanoamérica como de España con las corrientes innovadoras de Francia, Alemania, Inglaterra, Irlanda y otras naciones del Viejo Mundo. Lo que sí me parece un rasgo destacado de las letras latinoamericanas durante los años posteriores de floración original y sobresaliente, desde mediados del siglo XX; es la fecundación que la novela debe a la poesía. La literatura, decía Ángel Rama, ha venido ocupando la tierra por la imaginación. En este ámbito americano, a diferencia de otros, todo sucede como si la poesía y la novela no residieran en mundos separados, no fueran compartimentos estancos; y como si la fuerza del género no

${ }^{8}$ LORCA, Francisco García. Federico en persona. Madrid: Ed. M. Hernández, 1980, p. 187. 
impidiera la aparición de textos híbridos o fronterizos, que tan oportunamente expresan los desconciertos, las incertidumbres y las oportunidades del momento histórico que vivimos.

Ha sido posible también buscar en una lengua determinada una relación decisiva con el carácter dominante de un pueblo o una nación, o con la que se denominaba su genio, su alma o su temperamento. Es lo que se leía en Humboldt, Whorf o Cassirer. Rodó contemplaba una unidad moral e intelectual hispanoamericana que cimentara el desarrollo futuro de su "genio". En el fondo eran dos las hipótesis, la existencia de un carácter nacional y su correspondencia con las categorías de un sistema lingüístico. El gran arabista Emilio García Gómez, en un libro titulado Equivocos sobre la lengua y la cultura, ridiculizaba la idea de que el francés fuera la lengua del pensamiento lógico; y otras "tonterías" por el estilo." En esta ocasión lo que nos interesa es la opinión ante todo de los lingüistas, que ya no parecen inclinarse a favor del viejo concepto romántico. La definición de invariantes universales ha sido importante en la Lingüística del siglo pasado. ${ }^{10}$ "Es imposible mostrar", escribía Sapir, "que la forma de un idioma tenga la menor relación con el temperamento nacional". ${ }^{11}$ Además, las lenguas, las naciones y las etnias en muchos casos no coinciden, tan evidentemente en América como en Europa. Pocos piensan que una lengua determinada apresa toda la experiencia real de los hombres, tarea para la cual se ofrecen innumerables. variaciones y alternativas. ${ }^{12}$ Puede acaso sugerirse que el género, el que una palabra sea masculina o femenina, afecta la experiencia. El pecado es femenino en alemán, masculino en castellano. La muerte es masculina en alemán, pero femenina en castellano, italiano o francés, y en inglés no tiene género. ¿Son acaso éstas las condiciones culturales determinantes de nuestras concepciones o representaciones plásticas del pecado o de la muerte? Los recursos de la lengua se relacionan sin duda con las experiencias de unos hablantes, pero sin suprimir su libertad, sin impedir decir otra cosa, o pensar lo contrario, o

\footnotetext{
${ }^{9}$ Véase GÓMEZ, E. García. Equívocos sobre la lengua y la cultura. 2.ed. Valencia: 2001, p. 9.

${ }^{10}$ Véase GREENBERG, J. H. Universals of Language. Cambridge: Mass, 1963.

${ }^{11}$ Véase SAPIR, E. El lenguaje. México: 1956, p. 247.

${ }^{12}$ Véase ADRADOS, Francisco Rodríguez. Lingüistica estructural. Madrid: 1974, II, p. 754-758.
} 
desafiar las convenciones. Roman Jakobson subrayaba que los idiomas difieren esencialmente en lo que se ven obligados a expresar, y no en lo que pueden o no pueden expresar. ${ }^{13}$ En ruso hay que aclarar si una acción verbal se completó o no. En castellano tenemos que elegir entre haber "estado" y haber "sido". La morfología del verbo inglés no distingue con dos palabras entre dos formas verbales como "se equivocó" y "se equivocaba"; y por tanto no se traduce tan fácilmente aquel pareado de Rafael Alberti: "se equivocó la paloma,/ se equivocaba".No hay dos palabras diferentes en inglés que traduzcan perfectamente nuestros verbos "saber" y "conocer", pero la distinción entre los dos se puede formular sin dificultad. Y el gran Jakobson concluía que todo puede decirse en cualquier lengua.

Lo importante y prioritario hoy, según venimos recapitulando, es la perspectiva histórica, la percepción de continuidades y discontinuidades, la inteligencia del devenir, que se compadece mal con esa esencialidad que estorba gravemente el discurso sensato de la identidad.

Nuestro camino principal ha de pasar por la literatura, o al menos no puede eludir el encuentro con ella. Decíamos antes que el saber acerca de las letras o literaturas propias, o de la cultura propia - si nos empeñamos en usar este término, esta vez en su acepción $Y$, el universitario o ministerial, como conjunto o patrimonio de obras y prácticas artísticas e intelectuales -, es en realidad un proceso paulatino de autoconocimiento. Es lo que mostró ya con singular claridad y fuerza el excelente volumen llamado La literatura latinoamericana como proceso, publicado en Buenos Aires en 1985 y coordinado por la historiadora literaria y comparatista chilena Ana Pizarro. Ya dijo Carlos Fuentes en 1961 que la literatura latinoamericana componía un todo. Pero mucho quedaba por hacer. Recordando la enseñanza de Ángel Rama, que aunque la crítica no construye obras, sí puede construir una literatura, la investigación y el pensamiento crítico que ese volumen ejemplifica, junto con otros que han conducido también durante estos años a recapitulaciones y reflexiones de conjunto, abarca tanto el saber acerca del proceso histórico en el pasado de creación y desarrollo de la escritura misma, como el proceso de descubrimiento y

${ }^{13}$ Véase JAKOBSON, R. Ensayos de lingüistica general. Barcelona: 1984, p. 74. 
ordenación crítica, en el presente, de la tan abundante y diversa literatura latinoamericana. ${ }^{14}$ Se trata sin duda de un reto asombrosamente complejo, delicado y fascinante. De entrada las diferencias son muy importantes y lo que conviene no es borrarlas, sino entenderlas y absorberlas. No coinciden por fuerza con las fronteras nacionales los confines de unas áreas culturales principales, por ejemplo la zona andina que cubre el antiguo imperio quechua y hoy Bolivia, el Perú, Ecuador y el norte argentino. Ana Pizarro distingue entre tres sistemas superpuestos, uno culto o "erudito", otro popular, y otro, cuando lo hay, indígena; y además indica certeramente que la tarea historiográfica que estudia este "espesor" debe distinguir entre los diferentes ritmos de evolución de los diferentes estratos. ${ }^{15}$ "El ritmo temporal de una sobrevivencia maya no es el mismo que el ritmo temporal de una influencia neoclásica", explica Antonio Cándido, que ve además coincidencias entre los estilos primitivos y los de las vanguardias. ${ }^{16}$ Esta "temporalidad múltiple" matiza pero no suprime una amplia periodización, basada en épocas como la Formación, o período colonial, la Emancipación y luego los movimientos y corrientes de que hablábamos antes, como el Romanticismo, el Positivismo, el Modernismo, con la afirmación nacional posterior a la Revolución mexicana, etc.

A lo largo de esos años, esta gran "aventura intelectual de integración"17 detecta también un dinamismo que hoy puede interesarnos, el que tras el alejamiento de los modelos españoles durante el siglo XIX luego se aproxima a los grandes escritores de la primera mitad del Siglo XX, a Ortega, a Juan Ramón Jiménez y los poetas del 27. Este vaivén o movimiento pendular que caracteriza las relaciones entre una Iberoamérica relativamente autónoma y su compenetración no ya con el devenir español sino con la de los movimientos culturales europeos y occidentales, ofrece un modelo útil para quienes hoy interrogan las conexiones entre la cultura hispánica, en la acepción

\footnotetext{
${ }^{14}$ Véase RAMA, Ángel. PIZARRO, Ana. (ed.). La literatura latinoamericana como proceso. Buenos Aires: 1985. p. 85-97.

${ }_{15}^{15}$ PIZARRO, Ana. (ed.). La literatura latinoamericana como proceso. Buenos Aires: 1985. p. 18-21.

${ }^{16}$ CANDIDO, Antonio. PIZARRO, Ana. (ed.). La literatura latinoamericana como proceso. Buenos Aires: 1985, p. 44.

${ }^{17}$ Véase RAMA, Ángel. PIZARRO, Ana. (ed.). La literatura latinoamericana como proceso. Buenos Aires: 1985. p. 85-97.
} 
que vengo utilizando, la que pone de relieve la creatividad artística e intelectual, y las dimensiones de un mundo globalizado. Vaivén, movimiento dialéctico, mutuas influencias, proceso de cambio y mestizaje imprevisible, mejor que una línea simple e inexorable de evolución. Y papel decisivo, función creativa, de una cultura hispánica cuya integración creciente no es, a mi juicio, un vago sueño sino la dirección que contempla el futuro. La idea de literatura nacional ha caducado, como tarde o temprano la segregación entre los creadores de América Latina por un lado y los ibéricos por otro. Y el uso de tales categorías en las universidades contribuye a denunciar la terca distancia que separa la crítica literaria que en ellas se apoya y el mucho más vasto, diversificado y personal entorno en que respiran y trabajan los mejores poetas, novelistas y creadores.

El tema de la globalización es una invitación al pensamiento simple. Sólo me toca decir, puesto que aquí me he ocupado de premisas y modelos conceptuales, que son muchos lo que arrancan de una idea más compleja de la sociedad misma. Lévi-Strauss es para nosotros el apellido de un pensador eminente, pero en Tailandia, digamos, es una marca de pantalones vaqueros. Ni sé yo, por desgracia, lo reconozco, quiénes son los mejores pensadores y artistas tailandeses. Aludo ahora a la naturaleza estratificada de la sociedad misma. Es ésta un complejo envolvente que incluye un número de planos, que la consciencia analítica tiende a abreviar o a confundir. Son, reduciéndolos a unos pocos, el nivel religioso, el moral, el político, el económico, el social y el cultural. ${ }^{18}$ El desarrollo en el tiempo de cualquiera de esos estratos no es el mismo que el de los demás, ni tampoco su vinculación con el de ese mismo estrato en las naciones vecinas, sean próximas como el Uruguay o remotas como Tailandia. El tiempo real que vivimos es múltiple, según sugería el modelo de Ana Pizarro, o como el contrapunto del que hablaba Edward Said; y es distinto el grado de globalización, o su mera existencia, cuando pasamos de un nivel a otro.

Volviendo a la lengua, lo que está en juego es una forma de convivencia real que ella fundamenta y vivifica. Conmemorando estos días el Quijote y su carácter dialógico, hemos apreciado una vez más aquellos capítulos en que

\footnotetext{
${ }^{18}$ Véase ORTEGA Y GASSET, José. Europa y la idea de nación. Madrid: 1985. p. 45 y passim.
} 
tienen lugar unas simples conversaciones, en que la mutua comunicación ante todo sostiene unos modos de convivencia y de sociabilidad. Esta forma de relación interpersonal se nos aparece tanto más cervantina cuanto más o mejor muestra una satisfacción compartida, la alegría creativa de la palabra hablada, el encuentro de varios o de todos en un terreno felizmente común, que es la lengua.

Para leer mejor esos capítulos y entender mejor nuestra tarea, quisiera terminar recordando también a un gran sociólogo alemán de principios del siglo XX, Ferdinand Tönnies (1855-1936), que distinguió firmemente entre dos realidades, llamadas Gesellschaft y Gemeinschaftt, en castellano: sociedad y comunidad. La sociedad resulta del predominio de elementos construidos o artificiales, según Tönnies, que en el lugar de antiguas unidades como la tribu o la aldea conducen a conjuntos racionalmente estructurados como la ciudad y el Estado, fuentes palpables de injusticias y de crisis. La comunidad, o Gemeinschaft, es una realidad originaria, espontánea, natural, viva como un organismo, a la vez colectiva e íntima. La comunidad se expresa en actos de afirmación mutua, que representan "la unidad en la pluralidad", decía Tönnies, y "la pluralidad en la unidad". ${ }^{19}$

Esta comunidad de origen y de realidad que es la lengua espontáneamente compartida, la plenitud de la lengua viva que nos convida repetidamente, en cualquier lugar o ambiente, a la comunicación, a la amistad, y a través de la conversación, al diálogo, es lo que nos espera como objeto de conocimiento y origen de potenciaciones futuras. Ninguna comunidad puede prosperar auténticamente si se basa en el desconocimiento de sí misma. Y ninguna comunidad lingüística trae consigo la determinación o cortapisa ejercida por ninguno de sus miembros, porque la lengua es un estímulo constante para el impulso imaginativo y la libertad de creación.

\footnotetext{
${ }^{19}$ En una traducción reciente, véase TONNIES, Ferdinand. Community and Society. New Brunswick y Oxford, 1988. p. 33.
} 